\title{
Nebulized Corticosteroids in the Treatment of COPD Exacerbations: Systematic Review, Meta-Analysis, and Clinical Perspective
}

\author{
Roy A Pleasants PharmD, Tiansheng Wang MSc PharmD, Xiaohan Xu MSPharm, \\ Tatsiana Beiko MD MScR, He Bei MD, Suodi Zhai MSc, and M Bradley Drummond MD MHS
}

\begin{abstract}
BACKGROUND: COPD guidelines report that systemic corticosteroids are preferred over inhaled corticosteroids in the treatment of exacerbations, but the inhaled route is considered to be an option. OBJECTIVES: To conduct a systematic review and meta-analysis regarding the efficacy and safety of inhaled corticosteroids for COPD exacerbations. The second objective was to provide pharmacologic and clinical perspectives of inhaled corticosteroids for COPD exacerbations. METHODS: The primary outcome was a change in $\mathrm{FEV}_{1}$ baseline versus the last measured value. Secondary outcomes were a change in $\left(\mathrm{P}_{\mathrm{aO}_{2}}\right)$ and $\left(\mathrm{P}_{\mathrm{aCO}_{2}}\right)$ baselines versus the last measured values; $\mathrm{FEV}_{1}, \mathrm{P}_{\mathrm{aO}}$, and $\mathrm{P}_{\mathrm{aCO}}$ at 24 or $72 \mathrm{~h}$; and hyperglycemia. RESULTS: Each of the 9 studies included in the meta-analysis was conducted in subjects who were hospitalized and not critically ill. Our metaanalysis indicated that high-dose nebulized budesonide 4-8 $\mathrm{mg} / \mathrm{d}$ was noninferior to systemic corticosteroids on the change in $\mathrm{FEV}_{1}$ between baseline and the last measured value (mean difference of $0.05,95 \% \mathrm{CI}-\mathbf{0 . 0 1}$ to $0.12, P=.13$ ) and $\mathrm{P}_{\mathrm{aCO}_{2}}$ (mean difference of $-1.14,95 \% \mathrm{CI}-2.56$ to $0.27, P=.11$ ) but of inferior efficacy for $P_{a O}$ changes (mean difference of $-1.46,95 \%-2.75$ to $-0.16, P=.03$ ). Hyperglycemia was less frequent with high-dose nebulized budesonide (risk ratio, $0.13 ; 95 \%$ CI $0.03-0.46 ; P=.002)$. CONCLUSIONS: Based on our meta-analysis with a change in $\mathrm{FEV}_{1}$ as the primary end point, high-dose nebulized budesonide was an acceptable alternative to systemic corticosteroids in hospitalized subjects with COPD exacerbations who were not critically ill. Additional well-designed prospective studies are needed in both the acute care and ambulatory settings. We provide perspective on how this evidence might be applied in clinical practice. Key words: systemic corticosteroid; nebulization; pharmacology; meta-analysis; systematic review; budesonide. [Respir Care 2018;63(10):1302-1310. (C) 2018 Daedalus Enterprises]
\end{abstract}

\section{Introduction}

Corticosteroids are a standard treatment for exacerbations of COPD. The Global Initiative for Chronic Obstruc-

\footnotetext{
Dr Pleasants is affiliated with the Duke Clinical Research Institute, Durham, NC Pulmonary Department, and Durham VA Medical Center, Durham, North Carolina. Dr Wang is affiliated with the Chapel Hill School of Public Health, Chapel Hill, North Carolina. Ms Xiaohan Xu and $\mathrm{Mr}$ Suodi Zhai are affiliated with the Department of Pharmacy, Peking University Third Hospital, Beijing, China. Dr Beiko is affiliated with the Division of Pulmonary, Critical Care, Allergy and Sleep Medicine, Medical University of South Carolina, Charleston, South Carolina. Dr. Bei is affiliated with the Pulmonary Division, Third Hospital, Peking University Medical University, Beijing, China. Dr Drummond is affiliated with the Division of Pulmonary Diseases and Critical Care Medicine, University of North Carolina at Chapel Hill, Chapel Hill, North Carolina.
}

The authors have disclosed no conflicts of interest. tive Lung Disease guideline ${ }^{1}$ recommends systemic corticosteroids for the treatment of exacerbations. Systemic corticosteroids improve lung function and oxygenation, reduce treatment failures, and shorten hospital length of stay of patients with COPD exacerbations. ${ }^{2,3}$ The guidelines state that high-dose inhaled corticosteroids (ICS), specifically budesonide, seem to be as effective as systemic corticosteroids for COPD exacerbations. ${ }^{1}$ The spe-

\footnotetext{
Supplementary materials related to this paper are available at http:// www.rcjournal.com.

Correspondence: Roy A Pleasants PharmD, Duke University Clinical Research Institute, North Pavilion 2400 Pratt Street, Durham, NC 27705. E-mail: roy.pleasants@va.gov.
}

DOI: $10.4187 /$ respcare.06384 
cific patient categories that would benefit from high-dose ICS instead of systemic corticosteroids and other details have not been defined by the Global Initiative for Chronic Obstructive Lung Disease guidelines. ${ }^{1}$

Although systemic corticosteroids are the standard of care for COPD exacerbations, a better risk/benefit profile could result from the use of ICS with some comorbidities commonly found in COPD, 4 including diabetes mellitus and congestive heart failure as well as a history of steroidinduced psychosis. In the REDUCE trial, which evaluated systemic corticosteroids for COPD exacerbations, prednisone $40 \mathrm{mg}$ daily for $5 \mathrm{~d}$ caused new or worsening hyperglycemia in $>50 \%$ of subjects and worsening heart failure in $<10 \% 5$; biochemical adrenal suppression also was common. ${ }^{6}$ When considering the aforementioned issues and to provide additional guidance for clinicians who use the Global Initiative for Chronic Obstructive Lung Disease guideline $^{1}$ recommendations for ICS in exacerbations, we first presented the scientific basis by reviewing relevant clinical pharmacology and then reported a systematic review and meta-analysis of high-dose ICS. We aimed to assess the efficacy and safety of ICS compared with systemic corticosteroids in subjects who experienced COPD exacerbations. Also, we provided details about how clinicians might apply this evidence in selected patients experiencing an exacerbation.

\section{Pharmacology of Systemic Corticosteroids and ICS in the Treatment of COPD Exacerbations}

Pharmacologic mechanisms of corticosteroids in COPD exacerbations include anti-inflammatory effects, $\beta_{2}$-receptor modulation, and, in the case of inhaled agents, enhanced $\alpha-1$ adrenergic signaling in the airways, which led to vasoconstriction and decreased vascular exudation. ${ }^{7,8}$ In stable COPD, airway inflammation is dominated by neutrophilic infiltration, with increased numbers of macrophages and of $\mathrm{CD}^{+}$and $\mathrm{CD} 8^{+} \mathrm{T}$ lymphocytes. ${ }^{9}$ During exacerbations, sputum lymphocytes, neutrophils, and eosinophils can increase. ${ }^{10,11}$ In stable COPD, airway inflammation is dominated by neutrophilic infiltration, with increased numbers of macrophages as well as $\mathrm{CD}^{+}$and $\mathrm{CD}^{+}{ }^{+}$T lymphocytes. ${ }^{9}$

The anti-inflammatory effects of ICS in COPD are primarily based on chronically administered ICS, whereas little is published regarding acute effects. In subjects with COPD who received at least 1 month of ICS, a metaanalysis of 8 studies found that bronchoalveolar cell counts for $\mathrm{CD}^{+}$cells, $\mathrm{CD}^{+}$cells, neutrophils, and mast cells were significantly reduced, whereas macrophages were increased. ${ }^{12}$ ICS also seems to have systemic effects in COPD exacerbations including on $\mathrm{C}$-reactive protein, tissue necrosis factor alpha, serum cytokines, and adhesion molecules. ${ }^{13-15}$
Corticosteroids have significant effects on $\beta_{2}$ receptors in COPD, which affects subsensitivity that occurs with chronic high doses of $\beta_{2}$ agonists or in the presence of a viral respiratory tract infection. ${ }^{9}$ Therefore, by augmenting the effects of $\beta_{2}$ agonists, the addition of ICS serves as a means to help optimize bronchodilation. Although chronic ICS helps lessen reversal, downregulation of $\beta_{2}$ receptors still exists with chronic use of long-acting $\beta_{2}$ agonists. ${ }^{16}$

For ICS to be effective in COPD exacerbations, the onset of action should be similar to that of systemic corticosteroids. Studies that evaluated the onset of action of ICS on inflammation and $\beta_{2}$ receptors have principally been done in subjects with asthma and not in COPD. Whereas, the maximal effects of ICS may take weeks, ${ }^{17}$ initial pharmacologic effects can occur more quickly. ${ }^{18}$ Decreased airway blood flow, through enhanced alpha-1 adrenergic signaling, was found to occur within $15 \mathrm{~min}$ after ICS administration in subjects with stable asthma ${ }^{19}$ Therefore, it seems, based on the available evidence, that some anti-inflammatory effects of ICS can occur shortly after administration.

The onset of effects of ICS on $\beta_{2}$ receptors has also predominantly been investigated in asthma, whereas little has been conducted in COPD. In a study of subjects with stable asthma, corticosteroid-induced increases in accumulation of $\beta_{2}$ receptor messenger RNA occurred at $15 \mathrm{~min}$ and peaked at $2 \mathrm{~h} .{ }^{20}$ The increase in $\beta_{2}$-receptor numbers was slower and reached a maximum in $18-24$ h. ${ }^{20}$ Studies showed a rapid increase in $\mathrm{FEV}_{1}$ and peak expiratory flow. ${ }^{21,22}$ In a study of subjects with stable COPD that compared budesonide-formoterol with formoterol, greater bronchodilation occurred at $15 \mathrm{~min}$ with the combination, whereas at $1 \mathrm{~h}$ changes in $\mathrm{FEV}_{1}$ were similar. ${ }^{23}$

\section{Methods}

\section{Data Search and Selection Criteria}

We searched the PubMed, Embase, Clinicaltrials. gov, and Cochrane Library databases. The following key terms were used: COPD, high-dose, and ICS ("beclomethasone," "budesonide," "fluticasone propionate," "fluticasone furoate," "triamcinolone," "mometasone," and "flunisolide"), and randomized controlled trials. Details of our search strategy are provided in Appendix 1 (see the supplementary materials at http://www.rcjournal.com). We searched electronic databases from their inception through February 2018, with no restriction on language of publication. The study selection criteria were as follows: (1) randomized controlled trials in subjects with COPD exacerbation; (2) studies that compared ICS with systemic corticosteroids; and (3) studies that reported at least one of the following outcomes, which included pulmonary function measures (baseline and follow-up $\mathrm{FEV}_{1}$ ), changes in pre-broncho- 
dilator or trough $\mathrm{FEV}_{1}$, changes of arterial blood gases, and the occurrence of adverse events. Inhaled short-acting $\beta_{2}$ agonists and other background COPD medications were allowed.

\section{Outcome Measures}

The primary outcome for this meta-analysis was a change of $\mathrm{FEV}_{1}$ at baseline (on admission) versus the last measured value. A change in $\mathrm{FEV}_{1}$ was the primary outcome chosen by the investigators in all of the included studies and, therefore, was our principal measure of interest. Only 2 studies provided data at $24 \mathrm{~h},{ }^{28,31}$ whereas all reported $\mathrm{FEV}_{1}$ at the end of treatment. Secondary outcomes potentially included in the studies were changes in $\mathrm{P}_{\mathrm{aO}}$ and $\mathrm{P}_{\mathrm{aCO}}$ at baseline versus the last measured value, $\mathrm{FEV}_{1}$, $\mathrm{P}_{\mathrm{aO}}, \mathrm{P}_{\mathrm{aCO}_{2}}$ at a specific follow-up period (24 or $72 \mathrm{~h}$ ), and hyperglycemia. Limited data were available for dyspnea, FVC, peak expiratory flow, and relapse of exacerbations after treatment; therefore, these outcomes were not included in the meta-analysis. We also compared $\mathrm{FEV}_{1}$ of $\leq 5-\mathrm{d}$ and 7-d treatments of high-dose nebulized budesonide to explore the effect of different durations of therapy.

\section{Data Extraction}

Two of us (XX, RAP) independently reviewed the titles, abstracts, and citations of the studies. After screening potentially relevant studies, each independently evaluated the full reports for the eligibility based on study design, intervention, and outcomes. For each eligible study, we extracted study characteristics (author identification, study population, study design and duration, intervention and number of subjects, outcomes, and hospital length of stay and readmissions). For studies with missing SDs for the changes from baseline (included studies), ${ }^{15,26-32}$ we imputed SD by calculating a correlation coefficient from one of the studies. ${ }^{33}$ When a study had multiple arms for different dosing (eg, budesonide 4 and $8 \mathrm{mg} / \mathrm{d}$ ), we combined the arms of different dosing. ${ }^{32}$ For continuous outcomes, we calculated the weighted value for the combined intervention, and, for dichotomous outcomes (adverse events), we used the sum of adverse events in each arm.

\section{Assessment of Risk of Bias}

The Cochrane risk of bias tool was applied to assess the following sources of bias: (1) adequacy of sequence generation; (2) allocation concealment; (3) blinding of the participants, personnel, and outcome assessors; (4) incomplete outcome data; (5) selective outcome reporting; and (6) other biases. We evaluated incomplete outcome data and selective outcome reporting by efficacy and safety outcome, respectively. The following judgments were used: low risk, high risk, or unclear (either lack of information or uncertainty over the potential for bias). Two of us (XX, RAP) independently assessed the risk of bias and resolved disagreements by consensus, which involved a third one of us (TW) to resolve disagreements.

\section{Statistical Analysis}

We used Review Manager 5.3 (Cochrane Collaboration, Oxford, United Kingdom) for our meta-analyses, and the Cochran $\mathrm{Q}$ chi-square test and $\mathrm{I}^{2}$ statistic to assess heterogeneity among the studies. We selected a random-effects model because the observed effect estimates can vary across studies due to real differences in the treatment effect in each study as well as sampling variability. The results of the meta-analysis were expressed as weighted mean differences for continuous outcomes and as relative risks for dichotomous outcomes, both with $95 \%$ CIs. We performed subgroup analyses to examine different time points of $\mathrm{FEV}_{1}$ ( $24 \mathrm{~h}, 72 \mathrm{~h}$, final) to explore heterogeneity. We repeated all meta-analyses by using fixed-effect models in sensitivity analysis. Results were reported when they differed from the primary analysis. When quantitative synthesis of an outcome was not feasible, we qualitatively described the outcome. Publication bias was evaluated by the Egger test if $\geq 10$ studies were included in the analysis of the primary outcome. ${ }^{35}$

\section{Results}

The main electronic database search through February 2018 revealed 5,606 records after the search strategy was applied (Appendix 2 [see the supplementary materials at http://www.rcjournal.com]). After excluding studies that did not meet inclusion criteria, we obtained 10 relevant articles, including 2 additional records obtained from the study reference list, as shown in the flow chart (Appendix 3 [see the supplementary materials at http://www. rcjournal.com]). Of these, 9 prospective studies, ${ }^{15,26-33}$ which involved nearly 1,000 subjects hospitalized for COPD exacerbations, were included in the meta-analysis, however, depending on the specific analysis, fewer subjects were included. The only study conducted in the outpatient setting did not meet study criteria for inclusion in our analysis. ${ }^{36}$ The risk of bias among the studies is shown in Appendix 4 (see the supplementary materials at http:// www.rcjournal.com). The subjects' characteristics, the study design, interventions, and outcomes for the studies are presented in Appendix 5. All the studies compared high doses $(4-8 \mathrm{mg} / \mathrm{d})$ of nebulized budesonide to systemic corticosteroids (either oral prednisone-prednisolone or parenteral agents, eg, methylprednisolone); 3 of the studies included a placebo-control group. Most studies used a high-efficiency nebulizer. ${ }^{26-28,30,32,33}$ 


\section{INHALED CORTICOSTEROIDS FOR COPD EXACERBATIONS}

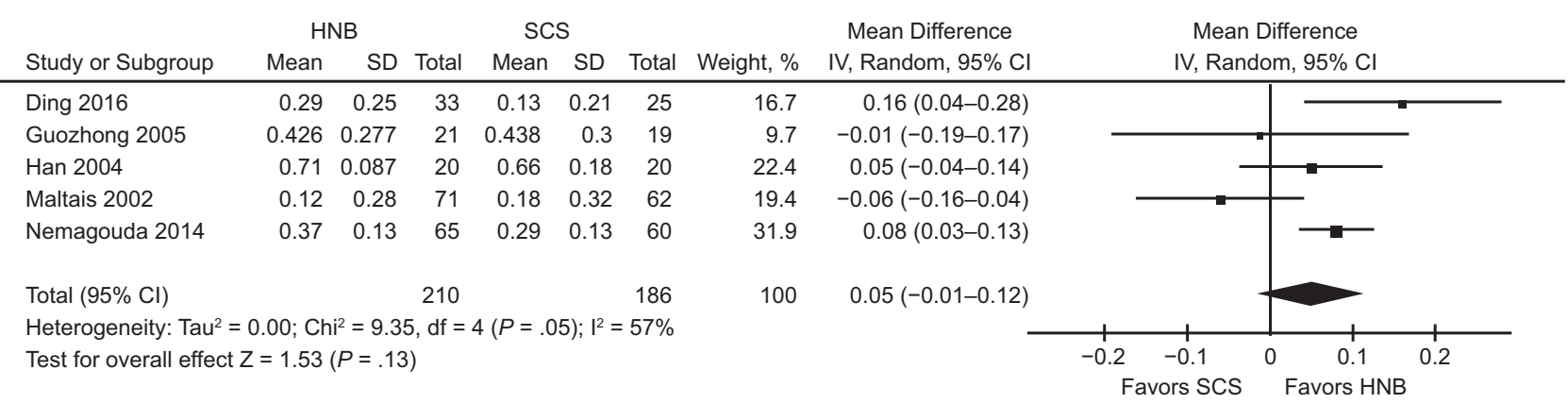

Fig. 1. Forest plot of the change in $\mathrm{FEV}_{1}(\mathrm{~L} / \mathrm{s})$ between baseline and the last measured value by using the random-effects model. $\mathrm{SCS}=$ systemic corticosteroid; HNB = high-dose nebulized budesonide.

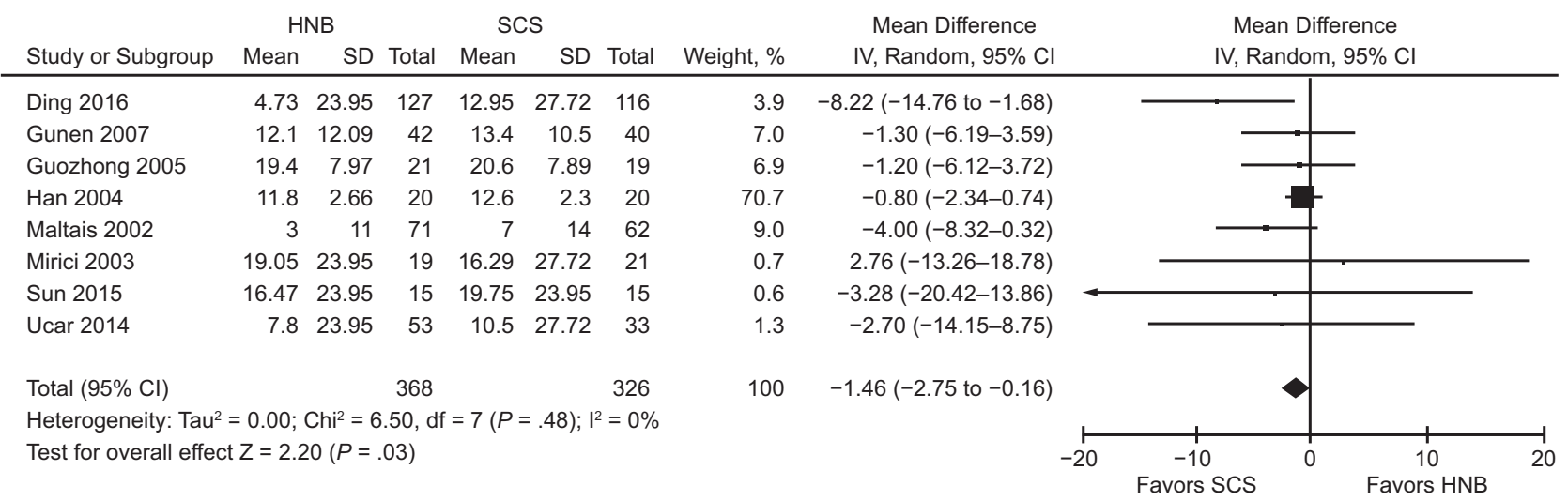

Fig. 2. Forest plot of change of $\mathrm{P}_{\mathrm{aO}}(\mathrm{mm} \mathrm{Hg})$ between baseline and the last measured value by using the random-effects model. SCS $=$ systemic corticosteroid; HNB = high-dose nebulized budesonide.

Despite the relatively large number of subjects included in these trials, not all the studies reported the outcomes of interest, and, therefore, a smaller number of subjects were involved in some of the individual outcomes. Notably, most studies excluded patients who had recent use of prednisone, ${ }^{26,27,30,33}$ required admission to an ICU, $26,27,31,33$ or had an exacerbation within $30 \mathrm{~d}$ of admission. ${ }^{30,32,33}$ Overall, the quality of the included trials was low to moderate; results for the risk of bias are shown in Appendix 3.

\section{Change in $\mathrm{FEV}_{1}$}

Our primary analysis showed that there was no significant difference in the change from baseline to the end of treatment $\mathrm{FEV}_{1}$ between high-dose nebulized budesonide and systemic corticosteroids (Fig. 1). There were no significant differences between groups in the change of $\mathrm{FEV}_{1}$ (mean difference of $0.05,95 \% \mathrm{CI}-0.01$ to $0.12, P=.08$ ) and the heterogeneity was moderate $\left(\mathrm{I}^{2}=57 \%\right)$. When using the fixed-effects model, the primary analysis showed that high-dose nebulized budesonide had a better efficacy (mean difference of 0.06, 95\% CI 0.03-0.10, $P<.001$ ). Change in $\mathrm{P}_{\mathrm{aO}_{2}}$ and $\mathrm{P}_{\mathrm{aCO}}$.
For the change in $\mathrm{P}_{\mathrm{aO}_{2}}$, there was a significant difference between the groups in the change from baseline to the last time measured $\mathrm{P}_{\mathrm{aO}_{2}}$, which favored systemic corticosteroids (mean difference of $-1.46,95 \% \mathrm{CI}-2.75$ to -0.16 , $P=.03$ ), with low heterogeneity $\left(\mathrm{I}^{2}=0 \%\right.$ ) (Fig. 2). For a change in $\mathrm{P}_{\mathrm{aCO}_{2}}$, however, we did not observe a significant difference between the baseline and the end of treatment (Fig. 3). When using the fixed-effect model, systemic corticosteroids showed better efficacy (mean difference of $-1.24,95 \% \mathrm{CI}-2.05$ to $-0.43, P=.003$ ).

\section{FEV ${ }_{1}, P_{a_{2}}$, and $P_{\mathrm{aCO}_{2}}$ at a Specific Follow-up Period}

For studies that reported $\mathrm{FEV}_{1}$ at 24 or $72 \mathrm{~h}$, pooled analysis showed that there was also no difference in $\mathrm{FEV}_{1}$ (Appendixes 6 and 7 [see the supplementary materials at http://www.rcjournal.com]). For studies that reported $\mathrm{P}_{\mathrm{aO}_{2}}$ and $\mathrm{P}_{\mathrm{aCO}}$, pooled analysis showed a significant difference in $\mathrm{P}_{\mathrm{aO}}$, that favored systemic corticosteroids (mean difference of $-1.72,95 \% \mathrm{CI}-2.90$ to $-0.54, P<.05$ ) (Appendix 8 [see the supplementary materials at http:// www.rcjournal.com]) but no difference in $\mathrm{P}_{\mathrm{aCO}_{2}}$ at $24 \mathrm{~h}$ (Appendix 9 [see the supplementary materials at http:// 
INHALED CORTICOSTEROIDS FOR COPD EXACERBATIONS

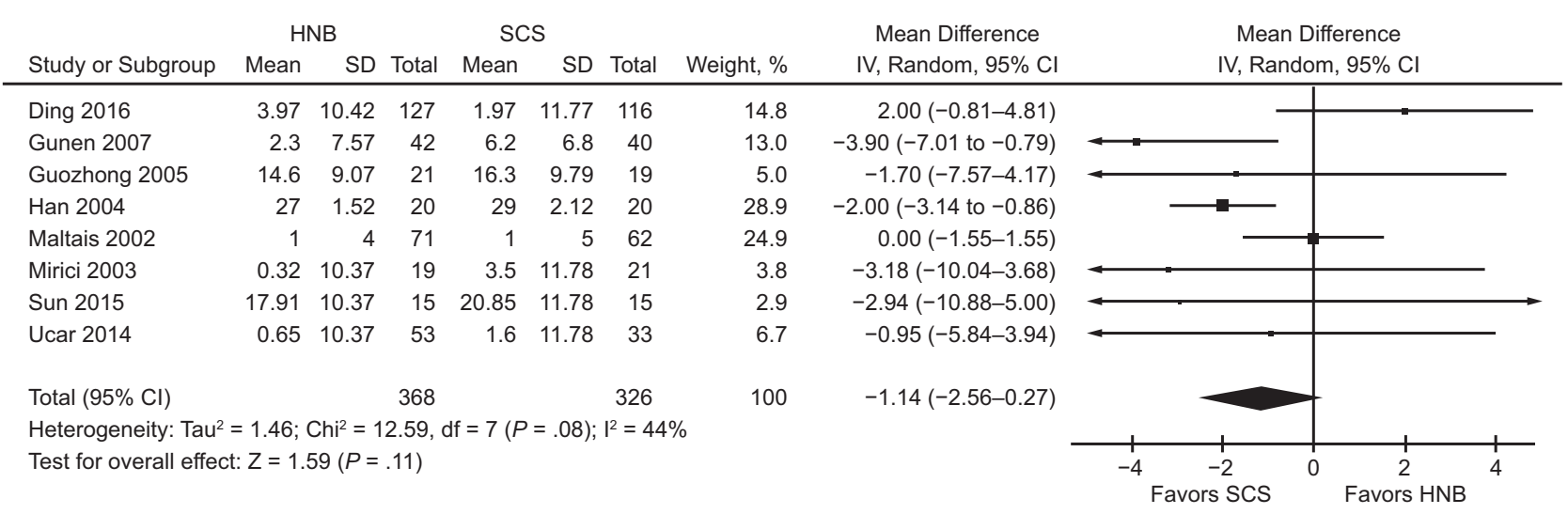

Fig. 3. Forest plot of change of $\mathrm{P}_{\mathrm{aCO}}(\mathrm{mm} \mathrm{Hg})$ between baseline and the last measured value by using the random-effects model. SCS $=$ systemic corticosteroid; HNB = high-dose nebulized budesonide.

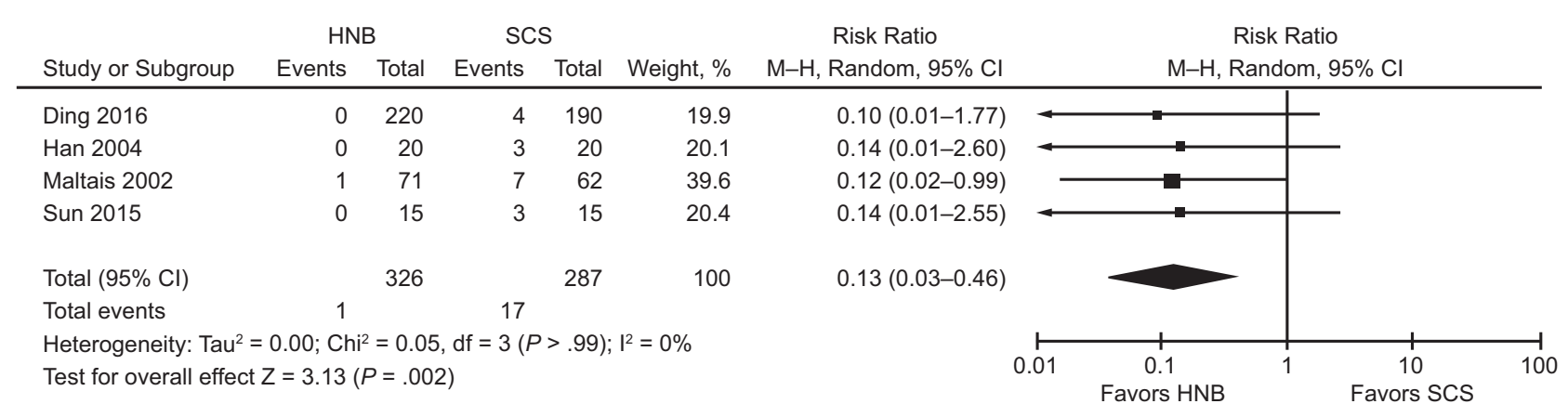

Fig. 4. Forest plot of pooled risk ratio for hyperglycemic events by using the random-effects model. SCS = systemic corticosteroid; HNB = high-dose nebulized budesonide.

www.rcjournal.com]). We also found that courses of highdose nebulized budesonide for $7 \mathrm{~d}$ were more efficacious than for $\leq 5 \mathrm{~d}$ (Appendix 10 [see the supplementary materials at http://www.rcjournal.com]).

\section{Safety}

We were able to include results from 4 studies ${ }^{15,26,28,33}$ about the frequency of hyperglycemia. There was a significant difference in hyperglycemia between high-dose nebulized budesonide and systemic corticosteroids use (relative risk 0.13, 95\% CI 0.03-0.46, $P<.05$ ) (Fig. 4). Candidiasis was reported in some studies, ${ }^{30,32}$ but we were unable to include this information in our meta-analysis.

\section{Additional Outcomes Not Included in Meta-Analysis}

Hospital length of stay was not included in the metaanalysis because of inconsistencies of the values reported among the studies. In studies that evaluated hospital length of stay, the percentage of subjects hospitalized for $>10 \mathrm{~d}$ were similar between high-dose nebulized budesonide and systemic corticosteroids (SC) or portion of subjects still hospitalized at a pre-determined time. ${ }^{26,30-33}$ No differences were found in dyspnea, ${ }^{26,31,32}$ COPD Assessment Test, ${ }^{33}$ or the St George Respiratory Questionnaire ${ }^{31}$ between treatments.

\section{Interpretation of Meta-Analysis}

All included studies only used nebulized budesonide at high doses and were conducted in the hospital setting. In addition, patients initially admitted to the ICU were excluded from enrollment in these studies. Based on a lowto-moderate quality level of evidence, the main finding of our meta-analysis was that high-dose nebulized budesonide provided similar improvement as systemic corticosteroids in pulmonary function $\left(\mathrm{FEV}_{1}\right)$ by the end of treatment (approaching discharge) in subjects with COPD exacerbations who were not critically ill and who were hospitalized; this was found for all included studies. Only 2 studies reported increases in $\mathrm{FEV}_{1}$ at $24 \mathrm{~h},{ }^{28,31}$ in which there was no difference between the treatments. The onset of action of high-dose nebulized budesonide in this setting was consistent with the rapid pharmacologic effects observed in studies of asthma. Further, as anticipated, hyperglycemia 
was less frequent with high-dose nebulized budesonide. Sensitivity analysis for the change in $\mathrm{FEV}_{1}$ shows that, when excluding each study (to explore each study's impact on a synthesized result) or when using fixed-effects model, a high-dose nebulized budesonide demonstrated equivalent or even superior efficacy to systemic corticosteroids, which further supported the results of our primary analysis. Our analysis largely agreed with another recent meta-analysis that included 3 of the studies; however, no difference was shown in $\mathrm{P}_{\mathrm{aO}_{2}}$ between the treatments. ${ }^{15,27,30,37}$

For secondary outcomes, systemic corticosteroids provided modestly greater benefits in $\mathrm{P}_{\mathrm{aO}_{2}}$ over high-dose nebulized budesonide $(<2 \mathrm{~mm} \mathrm{Hg}$, which equated to a $<5 \%$ difference between treatments), whereas there was no difference in $\mathrm{P}_{\mathrm{aCO}_{2}}$ values. Mean values for $\mathrm{P}_{\mathrm{aO}}$ in most studies were $>50 \mathrm{~mm} \mathrm{Hg}$, thus these differences between treatments were modest ( $<2 \%$ change) and, therefore, of uncertain clinical importance (Appendix 8). A sensitivity analysis showed that the significant result for $\mathrm{P}_{\mathrm{aO}_{2}}$ at $24 \mathrm{~h}$ was driven by the study by Han and $\mathrm{Zhao}^{28}$ (weight $89.5 \%$ ), which may have high risk of bias. Thus, we were unable to draw a conclusion on which therapy had the greatest effect on arterial blood gases in COPD exacerbations within the first $24 \mathrm{~h}$ of treatment.

Systemic adverse effects, such as hyperglycemia, elevated blood pressure, and fluid retention, are more common with oral and parenteral corticosteroids than with ICS. Comorbidities of diabetes mellitus, hypertension, obesity, and heart disease are extremely prevalent in individuals with COPD, and, therefore, adverse effects of systemic corticosteroids are potentiated in these subpopulations. ${ }^{4}$ In the studies included in this meta-analysis, the principal adverse effect reported was hyperglycemia, which occurred in $11.3-20.0 \%$ of the subjects who received systemic corticosteroids. However, because a number of the studies $^{27,32,33}$ excluded patients with diabetes mellitus, the actual rates of hyperglycemia with systemic corticosteroids were likely higher in the clinical setting.

In a study that used prednisone $40 \mathrm{mg}$ daily, similar to the dose for the meta-analysis studies, hyperglycemia occurred in more than half of hospitalized subjects with COPD exacerbations. ${ }^{5}$ We were unable to analyze differences in other adverse effects reported in these studies, such as pneumonia, worsening heart failure symptoms, or oral candidiasis, although the latter was reported more often with high-dose nebulized budesonide. In a study that compared high-dose nebulized budesonide with systemic corticosteroids in subjects with COPD and/or asthma, systemic markers (eg, osteocalcin) were significantly more altered with oral prednisolone. ${ }^{36}$ Also, there may also be benefits from the feeling of well-being with systemic corticosteroids, not achieved with ICS; however, this phenomenon would be difficult to assess.

\section{Limitations}

Some limitations of the pooled analysis should be recognized. First, we were only able to include 9 trials based on our inclusion criteria, although $>1,000$ subjects were included in the studies. For our primary end point $\left(\mathrm{FEV}_{1}\right)$, we were not able to include all the subjects in any single outcome measure for our meta-analysis. Also, inadequate blinding of the outcome assessment could result in overestimating the effects of an intervention. Ideally, there would have been more studies that reported measures at $24 \mathrm{~h}$ and thus would have allowed a better estimate of potential differences in onset of effects between the 2 therapies. In addition, the inability to include hospital length of stay in the meta-analysis was a significant limitation, although there were no apparent differences reported within the studies. Also, high-dose nebulized budesonide was the only therapy studied, whether our conclusions applied to other ICS or delivery devices was unknown.

\section{Clinical Application}

On the basis of the pharmacologic mechanisms of ICS and meta-analysis of high-dose nebulized budesonide studies in COPD exacerbations, we provided our perspectives as to how this information might be applied in the clinical setting, including patient selection, dosing, administration, and monitoring.

\section{Patient Selection}

Based on the clinical trials that compared these 2 therapies, high-dose nebulized budesonide and systemic corticosteroids, there was low-to-moderate evidence to support the use of high doses of nebulized budesonide in the following patients with COPD exacerbation: (1) if hospitalization was required, (2) if the severity of illness did not warrant ICU admission or invasive mechanical ventilation, (3) was not prednisone dependent, (4) had not experienced an exacerbation in the past $30 \mathrm{~d}$, and (5) had a history of glucose intolerance and/or diabetes mellitus. One study reported that subjects with COPD and diabetes mellitus were less likely to be prescribed systemic corticosteroids for COPD exacerbations, ${ }^{38}$ thus the concern for hyperglycemia could lead to undertreatment of COPD exacerbations in patients with diabetes.

Additional research is warranted for the use of highdose nebulized budesonide and other ICS at high doses as well as in certain clinical settings and patient types. First, there is increasing evidence that a combination of longacting anti-muscarinic agonist and long-acting $\beta_{2}$ agonist may provide greater clinical benefits than an ICS and a long-acting $\beta_{2}$ agonist combination. ${ }^{39}$ Under these circumstances, one therapeutic strategy may be to add ICS mono- 
therapy with the long-acting anti-muscarinic agonist and long-acting $\beta_{2}$ agonist combination rather than a triple inhaler. This would allow flexibility in adjusting the dose or initiating the ICS with the onset of a COPD exacerbation. However, this approach requires a prospective study in patients with COPD, and, in the United States, ICS monotherapy is not cleared by the FDA. Second, we are not able to make recommendations on the use of high-dose nebulized budesonide in patients with asthma and COPD overlap; although high-dose ICS has been shown to be effective in asthma exacerbations. ${ }^{40}$ In addition, there were few subjects in the high-dose nebulized budesonide studies reported to have heart failure, thus we were unable to assess safety in this type of patient. Systemic corticosteroids have been shown to worsen heart failure, ${ }^{41}$ largely through mineralocorticoid effects that lead to fluid retention.

We did not find any studies of high-dose ICS or highdose nebulized budesonide monotherapy for COPD exacerbations in the home setting or the emergency department. Further, there may be some patients for whom nebulized drug delivery may be suboptimal, such as patients with a tracheostomy, other factors that could significantly decrease lung deposition, or simply drug and administration costs. Drug costs are substantially different between oral prednisone and nebulized budesonide, and may need to be considered.

\section{Drug, Dose, and Administration}

The ICS used in the COPD exacerbation studies was budesonide, the only form of nebulized corticosteroid available in the United States ${ }^{42,43}$ Although high-dose ICS monotherapy administered by a multiple-dose inhaler has been studied in asthma exacerbations, ${ }^{40}$ this is not the case for COPD. A study, not included in this meta-analysis, of budesonide-formoterol dry powder inhaler in subjects with asthma or COPD exacerbations found that inhaled therapy was as effective as systemic corticosteroids. ${ }^{36}$ Inhaled dexamethasone has been studied in asthma ${ }^{44}$ but, to our knowledge, not in COPD.

For studies included in the meta-analysis, total daily nebulized budesonide doses were 4,6 , and $8 \mathrm{mg}$, administered every 6 to $12 \mathrm{~h}$. There was a proportional distribution among the different doses used (Appendix 5). Although not adequately powered, one study found no difference in outcomes between $4 \mathrm{mg}$ and $8 \mathrm{mg}$ daily. ${ }^{32}$ The dose chosen may depend on costs and the nebulizer chosen. The duration of therapy of high-dose nebulized budesonide was not consistent among the studies. Our analysis of high-dose nebulized budesonide treatment for $\leq 5 \mathrm{~d}$ and $7 \mathrm{~d}$ showed that $\mathrm{FEV}_{1}$ can be improved more with the duration of $7 \mathrm{~d}(P<.001)$; however, this was based on only 2 studies (Appendix 10).28,29 Clinical mon- itoring for a patient who receives high-dose nebulized budesonide would be similar to that for systemic corticosteroids except for blood glucose; however, oropharyngeal adverse effects may be more likely for the former. Although not described in the meta-analysis studies, albuterol and ipratropium nebulized solutions are physiochemically compatible with budesonide, thus could be admixed, depending on the volume of the nebulizer. ${ }^{45}$

Among the studies included in our meta-analysis, highefficiency, breath-enhanced small-volume nebulizers Portaneb Ventstream (Portaneb Ventstream, Respironics, West Sussex) and Pari LC Plus (Pari Respiraory Equipment, Midlothian, Virginia) were the most commonly used (Appendix 5). Compared with traditional T-tube updraft nebulizers, these venturi-type devices generate a more-optimal particle size and have an increased fraction of drug delivered in the lung. ${ }^{46,47}$ The higher doses of ICS and more-efficient delivery may be advantageous in the setting of a patient with severe air-flow obstruction, such as in an patient with advanced COPD who is experiencing an exacerbation. The package inserts for nebulized budesonide recommend the high-efficiency Pari LC Plus (Astra Zeneca and Teva) by a jet nebulizer. ${ }^{43,44}$ Ultrasonic nebulizers are not recommended to administer budesonide. ${ }^{43,44}$ Compressor flow should be approximately $6 \mathrm{~L} / \mathrm{min}$. The mass median aerodynamic diameter of budesonide for the Pari LC Plus and the Respironics Ventstream, $4.1 \mu \mathrm{m}$ and $3.1 \mu \mathrm{m}$, respectively, are clearly within the respirable range. ${ }^{47}$ These nebulizers have a greater predicted lung delivery but may have longer treatment times because there is less wastage during the patient's expiration. One consideration is the volume of drug to be nebulized and the maximum volume of the nebulizer, typically $8 \mathrm{~mL}$. There are 3 budesonide strengths, $0.25,0.5$, and $1 \mathrm{mg}$ per $2 \mathrm{~mL}$, and, when using higher doses and when considering the maximum volume for the nebulizer, the $1 \mathrm{mg}$ per $2 \mathrm{~mL}$ formulation is preferred.

\section{Conclusions}

Our meta-analysis found that high-dose nebulized budesonide seems to be noninferior to systemic corticosteroids in the treatment of COPD exacerbations based on $\mathrm{FEV}_{1}$ as the primary outcome measure, which supports current Global Initiative for Chronic Obstructive Lung Disease guideline ${ }^{1}$ recommendations for this therapy as an alternative to systemic steroids. All 9 studies showed comparable clinical effects between high-dose nebulized budesonide and systemic corticosteroids in COPD exacerbations. Pulmonary function improved rapidly and comparably between the nebulized and systemic corticosteroid therapies. There was a slightly greater improvement in $\mathrm{P}_{\mathrm{aO}}$ with systemic corticosteroids, but the difference was modest $(<2 \mathrm{~mm} \mathrm{Hg})$, whereas no statistical differences were ev- 


\section{INHALED CORTICOSTEROIDS FOR COPD EXACERBATIONS}

ident for $\mathrm{P}_{\mathrm{aCO}}$, and, similarly, the change was modest $(<2 \mathrm{~mm} \mathrm{Hg})$. There was only evidence for high-dose budesonide administered by high-efficiency nebulizers in patients with COPD exacerbations who required hospitalization and not patients in the home, emergency department, or ICU settings. Compared with systemic corticosteroids, high-dose nebulized budesonide was less likely to cause hyperglycemia, therefore, patients with diabetes may benefit from the inhaled route. Additional well-designed research is needed to substantiate these studies and also to determine the efficacy in other settings as well as in patients with asthma-COPD overlap and congestive heart failure.

\section{REFERENCES}

1. goldcopd.org/gold-2017-global-strategy-diagnosis-managementprevention-copd. Accessed May 15, 2017.

2. Davies L, Angus RM. Calverley PM. Oral corticosteroids in patients admitted to hospital with exacerbations of chronic obstructive pulmonary disease: a prospective randomised controlled trial. Lancet 1999;354(9177):456-460

3. Niewoehner DE, Erbland ML, Deupree RH, Collins D, Gross NJ, Light RW, et al. Effect of systemic glucocorticoids on exacerbations of chronic obstructive pulmonary disease. Department of Veterans Affairs Cooperative Study Group. N Engl J Med 1999;340(25):19411947.

4. Divo M, Cote C, de Torres JP, Casanova C, Marin JM, Pinto-Plata $\mathrm{V}$, et al; BODE Collaborative Group. Comorbidities and risk of mortality in patients with chronic obstructive pulmonary disease. Am J Respir Crit Care Med 2012;186(2):155-161.

5. Leuppi JD, Schuetz P, Bingisser R, Bodmer M, Briel M, Drescher T, et al. Short-term vs conventional glucocorticoid therapy in acute exacerbations of chronic obstructive pulmonary disease: the REDUCE randomized clinical trial. JAMA 2013;309(21):2223-2231.

6. Schuetz P, Leuppi JD, Bingisser R, Bodmer M, Briel M, Drescher T, et al. Prospective analysis of adrenal function in patients with acute exacerbations of COPD: the reduction in the use of corticosteroids in exacerbated COPD (REDUCE) trial. Eur J Endocrinol 2015;173(1): 19-27.

7. Barnes PJ. Inhaled corticosteroids. Pharmaceuticals 2010;3(3):514540 .

8. Horvath G, Wanner A. Inhaled corticosteroids: effects on the airway vasculature in bronchial asthma. Eur Respir J 2006;27(1):172-187.

9. Barnes PJ. Inflammatory mechanisms in patients with chronic obstructive pulmonary disease. J Allergy Clin Immunol 2016;138(1): 16-27.

10. Papi A, Bellettato CM, Braccioni F, Romagnoli M, Casolari P, Caramori $\mathrm{G}$, et al. Infections and airway inflammation in chronic obstructive pulmonary disease severe exacerbations. Am J Respir Crit Care Med 2006;173(10):1114-1121.

11. Hurst JR, Perera WR, Wilkinson TM, Donaldson GC, Wedzicha JA. Systemic and upper and lower airway inflammation at exacerbation of chronic obstructive pulmonary disease. Am J Respir Crit Care Med 2006;173(1):71-78.

12. Jen R, Rennard SI, Sin DD. Effects of inhaled corticosteroids on airway inflammation in chronic obstructive pulmonary disease: a systematic review and meta-analysis. Int J Chron Obstruct Pulmon Dis 2012;7:587-595.

13. Man SF, Xuekui Zhang, Vessey R, Walker T, Lee K, Park D, Sin DD. The effects of inhaled and oral corticosteroids on serum inflam- matory biomarkers in COPD: an exploratory study. Ther Adv Respir Dis 2009;3(2):73-80.

14. Makarova EV, Varvarina GN, Menkov NV, Czapaeva MY, Lazareva ES, Kazatskaya ZA, et al. [Nebulized budesonide in the treatment of exacerbations of chronic obstructive pulmonary disease: efficacy, safety, and effects on the serum levels of soluble differentiation molecules.] Ter Arkh 2016;88(3):24-31.

15. Sun X, He Z, Zhang J, Deng J, Bai J, Li M, Zhong X. Compare the efficacy of inhaled budesonide and systemic methylprednisolone on systemic inflammation of AECOPD. Pulm Pharmacol Ther 2015;31: 111-116.

16. Booth H, Bish R, Walters J, Whitehead F, Walters EH. Salmeterol tachyphylaxis in steroid treated asthmatic subjects. Thorax 1996; 51(11):1100-1104.

17. Valthenen AS, Knox AJ, Wisniewski A, Tattersfield AE. Time course of change in bronchial reactivity with an inhaled corticosteroid in asthma. Am Rev Respir Dis 1991;143(6):1317-1321.

18. Usmani OS, Ito K, Maneechotesuwan K, Ito M, Johnson M, Barnes PJ, Adcock I. Glucocorticoid receptor nuclear translocation in airway cells after inhaled combination therapy. Am J Respir Crit Care Med 2005;172(6):704-712.

19. Mendes ES, Rebolledo P, Campos M, Wanner A. Immediate antiinflammatory effects of inhaled budesonide in patients with asthma. Ann Am Thorac Soc 2014;11(5):706-711.

20. Mak JC, Nishikawa M, Barnes PJ. Glucocorticosteroids increase beta 2-adrenergic receptor transcription in human lung. Amer J Physiol 1995;268(1):L41-L46.

21. Gibson PG, Saltos N, Fakes K. Acute anti-inflammatory effects of inhaled budesonide in asthma. Am J Respir Crit Care Med 2001; 163(1):32-36

22. Ellul-Micallef R, Johansson SA. Acute dose-response studies in bronchial asthma with a new corticosteroid, budesonide. Br J Clin Pharmacol 1983;15(4):419-422.

23. Cazzola M, Santus P, Di Marco F, Carlucci P, Mondoni M, Materra MG, Centanni S. Onset of action of formoterol/budesonide in singe inhaler vs. formoterol in patients with COPD. Pulm Pharmacol Ther 2004; 17(3):121-125.

24. Daley-Yates PT. Inhaled corticosteroids: potency, dose equivalence and therapeutic index. Br J Clin Pharmacol 2015;80(3):372-380.

25. Kharitonov SA, Donnelly LE, Montuschi P, Corradi M, Collins JV, Barnes PJ. Dose-dependent onset and cessation of action of inhaled budesonide on exhaled nitric oxide and symptoms in mild asthma. Thorax 2002;57(10):889-896.

26. Maltais F, Ostinelli J, Bourbeau J, Tonnel AB, Jacquemet N, Haddon $\mathrm{J}$, et al. Comparison of nebulized budesonide and oral prednisolone with placebo in the treatment of acute exacerbations of chronic obstructive pulmonary disease: a randomized controlled trial. Am J Respir Crit Care Med 2002;165(5):698-703.

27. Mirici A, Meral M, Akqun M. Comparison of the efficacy of nebulised budesonide with parenteral corticosteroids in the treatment of acute exacerbations of chronic obstructive pulmonary disease. Clin Drug Investig 2003;23(1):55-62.

28. Han W, Zhao X. Nebulized budesonide in the treatment of acute exacerbations of chronic obstructive pulmonary disease. J Clin Med Pract 2004;8(12):6-8

29. Guozhong C, Hui W, Qi Z, Fuliang W. The effect of inhaled budesonide in persons with acute excerbations of chronic obstructive pulmonary disease. Chin General Pract 2005;8:1667-1668.

30. Gunen H, Hacievliyagil SS, Yetkin O, Gulbas G. The role of nebulised budesonide in the treatment of acute exacerbations of COPD. Eur Respir J 2007;29(4):660-667.

31. Nemagouda S. Clinical efficacy of nebulized budesonide in acute exacerbation of COPD. J Evol Med Dental Sci 2014;3(15):41214131. 


\section{INHALED CORTICOSTEROIDS FOR COPD EXACERBATIONS}

32. Yilmazel Ucar E, Araz O, Meral M, Sonkaya E, Saglam L, Kaynar $\mathrm{H}$, et al. Two different dosages of nebulized steroid versus parenteral steroid in the management of COPD exacerbations. a randomized control trial. Med Sci Monit 2014;20:513-520.

33. Ding Z, Li X, Lu Y, Rong G, Yang R, Zhang R, et al. A randomized, controlled multicentric study of inhaled budesonide and intravenous methylprednisolone in the treatment on acute exacerbation of chronic obstructive pulmonary disease. Respir Med 2016;121:39-47.

34. Higgins JP, Green S, editors Special topics in statistics. Cochrane handbook for systematic reviews of interventions. Version 5.1.0 [updated Mar 2011]. The Cochrane Collaboration, 2011. http:// handbook.cochrane.org. Accessed May 2, 2017.

35. Beeh KM, Beier J, Donohue JF. Clinical trial design in chronic obstructive pulmonary disease: current perspectives and considerations with regard to blinding of tiotropium. Respir Res 2012;13:52.

36. Sterne J, Egger M, Moher D. Addressing reporting biases. In: Higgins JP, Green S, editors. Cochrane handbook for systematic reviews of interventions. Version 5.1.0 [updated Mar 2011] The Cochrane Collaboration, 2011. http://handbook.cochrane.org. Accessed February 1,2018 .

37. Morice AH, Morris D, Lawson-Matthew P. A comparison of nebulized budesonide with oral prednisolone in the treatment of exacerbations of obstructive pulmonary disease. Clin Pharmacol Ther 1996; 60(6):675-678.

38. Zhai Y, Zhang H, Sun T, Ye M, Liu H, Zheng R. Comparative efficacies of inhaled corticosteroids and systemic corticosteroids in treatment of chronic obstructive pulmonary disease exacerbations: a systematic review and meta-analysis. J Aerosol Med Pulm Drug Deliv 2017;30(5):289-298.
39. Pleasants R, Herrick H, Liao W, Ohar J. Use of a US populationbased survey to describe the relationship of COPD and co-morbidities [abstract]. Eur Respir J 2011;38(Suppl 55):1025.

40. Magnussen H, Disse B, Rodriguez-Roisin R, Kirsten A, Watz H, Tetzlaff $\mathrm{K}$, et al: WISDOM Investigators. Withdrawal of inhaled glucocorticoids and exacerbations of COPD. N Engl J Med 2014; 371(14):1285-1294.

41. Alangari AA. Corticosteroids in the treatment of acute asthma. Ann Thorac Med 2014;9(4):187-192.

42. Greene MA, Gordon A, Boltax AJ. Clinical and cardiodynamic effects of adrenocortical steroids in congestive heart failure. Circulation 1960;21:661-671.

43. Pulmicort Respules [package insert]. Wilmington, DE: Astra Zeneca Pharmaceuticals LP; 2009.

44. Budesonide inhalation suspension [package insert]. North Wales, PA: Teva Pharmaceuticals USA, Inc.; 2016.

45. Scarfone RJ, Loiselle JM, Wiley JF II, Decker JM, Henretig FM, Joffe MD. Nebulized dexamethasone versus oral prednisone in the emergency treatment of asthmatic children. Ann Emerg Med 1995; 26(4):480-486.

46. McKenzie JE, Cruz-Rivera M. Compatibility of budesonide inhalation suspension with four nebulizing solutions. Ann Pharmacother 2004;38(6):967-972.

47. Devadason SG, Everard ML, Linto JM, Le Souëf PN. Comparison of drug delivery from conventional versus "Venturi" nebulizers. Eur Respir J 1997;10(11):2479-2483.

48. Barry PW, O'Callaghan C. An in vitro analysis of the output of budesonide from different nebulizers. J Allergy Clin Immunol 1999; 104(6):1168-1173. 